\title{
Temozolomide with Radiation Therapy in High Grade Brain Gliomas: Pharmaceuticals Considerations and Efficacy; A Review Article
}

\section{Georgios V. Koukourakis ${ }^{1, *}$, Vassilios Kouloulias ${ }^{1}$, Georgios Zacharias ${ }^{1}$, Christos Papadimitriou ${ }^{2}$, Panagiotis Pantelakos ${ }^{1}$, George Maravelis ${ }^{1}$, Andreas Fotineas ${ }^{1}$, Ivelina Beli ${ }^{1}$, Demetrios Chaldeopoulos ${ }^{1}$ and John Kouvaris ${ }^{3}$}

1 Attikon University Hospital of Athens, Second Radiology Department, Radiation Therapy Unit, Medical School of Athens, Greece; E-mails: vkouloul@cc.ece.ntua.gr (V.K.), georgios_zaharias@yahoo.gr (G.Z.),panpan@otenet.gr (P.P.), maravelis@gmail.com (G.M.), viridan55@hotmail.com (A.F.), kbelis@in.gr (I.B.),dhal@her.forthnet.gr (D.C.)

2 University of Athens, Medical Oncology Unit, Alexandra Hospital Athens Greece; E-mail: chrpapadim@yahoo.gr (C.P.)

3 Aretaieion University Hospital, $1^{\text {st }}$ Radiology Department, Radiation Therapy Unit, Medical School of Athens, Greece; E-mail: johnkouv@aretaieio.uoa.gr (J.K.)

* Author to whom correspondence should be addressed; Email: gkoyokoyrakis@yahoo.gr.

Received: 12 March 2009; in revised form: 10 April 2009 / Accepted: 15 April 2009 /

Published: 16 April 2009

\begin{abstract}
Malignant gliomas (glioblastoma multiforme and anaplastic astrocytoma) which have a combined incidence of 5-8/100,000 population, represent the most common primary central nervous system tumors. The treatment outcomes even with aggressive approach including surgery, radiaton therapy and chemotherapy are dismal with median reported survival is less than 1 year. Temozolomide is a new drug which has shown promise in treating malignant gliomas and other difficult-to-treat tumors. This drug is a per os (p.o) imidazotetrazine second-generation alkylating agent which represents the leading compound in a new class of chemotherapeutic agents that enter the cerebrospinal fluid and do not require hepatic metabolism for activation.

The efficacy of temozolomide was tested in vitro studies and has demonstrated schedule-dependent antitumor activity against highly resistant malignancies, including high-grade glioma (HGG). In addition, in clinical studies, temozolomide consistently demonstrates reproducible linear pharmacokinetics with approximately $100 \%$ p.o.
\end{abstract}


bioavailability, noncumulative minimal myelosuppression that is rapidly reversible, and activity against a variety of solid tumors in both children and adults. Moreover, preclinical studies have evaluated the combination of temozolomide with other alkylating agents and inhibitors of the DNA repair protein $O^{6}$-alkylguanine alkyltransferase to overcome resistance to chemotherapy in malignant glioma and malignant metastatic melanoma. At the present time temozolomide is approved in the United States for the treatment of adult patients with refractory anaplastic astrocytoma and, in the European Union, for treatment of glioblastoma multiforme showing progression or recurrence after standard therapy. Temozolomide's characteristics which make it a candidate for a wide range of clinical testing to evaluate the potential of combination treatments in different tumor types are its predictable bioavailability and minimal toxicity. An overview of the mechanism of action of temozolomide and a summary of results from more important randomized controlled clinical trials in high grade gliomas are presented here.

Key words: Temozolomide; Malignant gliomas; Chemotherapy; Radiation therapy.

\section{Introduction}

Temozolomide (TMZ; Temodar ${ }^{\mathrm{TM}}$ [Temodal $^{\mathrm{TM}}$ in the United Kingdom and Europe], ScheringPlough Corporation; Kenilworth, NJ) is a novel oral alkylating agent that has shown efficacy in the treatment of a variety of solid tumors, including primary malignant brain tumors [1-7]. TMZ has certain advantages over many existing alkylating agents because of its unique chemical structure and pharmacokinetic properties [8,9]. Because of its small molecular weight, TMZ efficiently crosses the blood brain barrier and is effective against primary brain tumors [10]. In addition, TMZ can be administered orally without dietary restrictions, and essentially $100 \%$ of the orally administered dose enters the blood flow. TMZ is also associated with a low incidence of severe adverse events. Unlike nitrosoureas and other alkylating agents that chemically cross-link the DNA and are associated with severe, doselimiting, cumulative hematologic toxicity, TMZ is associated with generally mild, noncumulative myelosuppression.

In Phase 1 and 2 clinical studies conducted by the CRC (London, United Kingdom), temozolomide was absorbed rapidly, exhibited $100 \%$ p.o. bioavailability within $1-2 \mathrm{~h}$ of administration, and demonstrated antineoplastic activity in recurrent high-grade glioma [11-14]. Results of these trials showed that when temozolomide is administered p.o. once daily for 5 days in a 4-week cycle, it is well tolerated, producing mild-to-moderate toxicity that is both expected and easily managed. The results also confirmed the ability of temozolomide to penetrate the CNS (central nervous system) and indicated that temozolomide has considerable potential in treating gliomas and improving the QOL (quality of life) of patients with glioma [13-15]. Additional Phase 1 studies have confirmed these results and have extended these observations to pediatric patients [16,17].

Temozolomide has been evaluated in a number of Phase 2 and 3 clinical trials for the treatment of glioblastoma multiforme and anaplastic astrocytoma, malignancies for which there are no satisfactory therapies. On the basis of the results of these studies, temozolomide has been approved in the 
European Union for the treatment of patients with glioblastoma multiforme showing progression or recurrence after standard therapy. Moreover, temozolomide received accelerated approval from the FDA (food and drug administration) for treatment of adult patients with anaplastic astrocytoma who have relapsed after treatment that included a nitrosurea drug (BCNU or CCNU) and procarbazine. Recently, FDA gave full approval for temozolomide as first line treatment for glioblastoma, a decision followed by the EMEA (European Medicines Agency). Studies are under way to evaluate the combination of temozolomide with other chemotherapeutic agents and biochemotherapy in the treatment of malignant glioma, respectively. This article reviews the mechanism of action of temozolomide as an anticancer agent and summarizes the most recent clinical studies of temozolomide for the treatment of malignant gliomas.

\section{Materials and Methods}

\section{Identification of Eligible Studies}

We searched MEDLINE and the Cochrane Central Register of Controlled Trials (last search on January 2009) using combinations of terms, such as: temozolomide, malignant gliomas, radiation therapy and treatment. We considered all meta-analysis or randomized controlled trials providing information about the effectiveness of temozolomide on treatment of malignant gliomas, its adverse profile effects, its dosage and administration, and future directions of ongoing research as eligible.

\section{Data Extraction}

We have incorporated as eligible in this review all randomized controlled trails that had two arms: first arm, intervention, patients that had received radiation therapy comcomitant with temozolomide and second arm, comparison, patients that had received radiation therapy only or radiation therapy in association with other form of chemotherapy e.g PCV, Gliadel. The primary outcomes were survival from time to randomization to time of death, and secondary were: time to progression, quality of life and adverse events. We have extracted information from each eligible study. The data recorded, included author's name, year of publication, number of patients included in the study, treatment schedule, percentage overall response, median time to progression and median survival.

\section{Chemical structure and mechanism of action}

TMZ belongs to the imidazotetrazine family, which is a new class of alkylating agents. These compounds contain an imidazole ring and are structurally and functionally similar to DTIC (dacarbazine), which is a member of the triazene subgroup [9]. TMZ was first synthesized by Stevens and coworkers in 1984 [8], and they were the first to demonstrate that TMZ had anticancer activity $[8,18]$. TMZ is a small molecule with a molecular weight of 194 Daltons and is, therefore, readily absorbed in the digestive tract and, because it is lipophilic, it is able to cross the blood-brain barrier. $\mathrm{TMZ}$ is highly stable at the acidic $\mathrm{pH}$ of the stomach. Nevertheless, once in contact with the slightly basic $\mathrm{pH}$ of the blood and tissues, TMZ spontaneously undergoes hydrolysis to the active metabolite MTIC [5-(3-dimethyl-1-triazenyl)imidazole-4-carboxamide], which rapidly breaks down to form the reactive methyldiazonium ion (Figure 1) [9]. Penetration of TMZ into the CNS has been studied in rats 
and rhesus monkeys, and these studies have shown that the levels of drug in the brain and cerebrospinal fluid are approximately $30 \%$ to $40 \%$ of the plasma concentration [10]. The first human pharmacokinetic study on TMZ to quantify CSF penetration was conducted by Ostermann et al. [19]. They have assessed TMZ pharmacokinetics in plasma and cerebrospinal fluid (CSF) along with its interindividual variability, to characterize covariates and to explore relationships between systemic or cerebral drug exposure and clinical outcomes. The authors have concluded that the area under the concentration-time curve (AUC), $\mathrm{AUC}_{\mathrm{CSF}} / \mathrm{AUC}_{\text {plasma }}$ ratio was $20 \%$ and that systemic or cerebral exposures are not better predictors than the cumulative dose alone for both efficacy and safety. The metabolite MTIC, however, does not effectively penetrate the CNS.

The methyldiazonium ion formed by the breakdown of MTIC primarily methylates guanine residues in the DNA molecule, resulting in the formation of $O^{6}$ - and $N^{7}$-methylguanine. The formation of O6-methylguanine is primarily responsible for the cytotoxic effects of TMZ and DTIC. When DNA mismatch repair enzymes attempt to excise $O^{6}$-methylguanine, they generate single- and double-strand breaks in the DNA, leading to activation of apoptotic pathways. $N^{7}$-methylguanine is comparatively less cytotoxic because the nucleotide excision repair pathway can successfully excise these adducts without damaging the DNA. TMZ does not result in chemical cross-linking of the DNA strands. Thus, it is less toxic to the hematopoietic progenitor cells in the bone marrow than are the nitrosoureas (i.e., carmustine, lomustine), platinum compounds, and procarbazine, which do cross-link the DNA.

Figure 1. Metabolism of temozolomide to its active form.

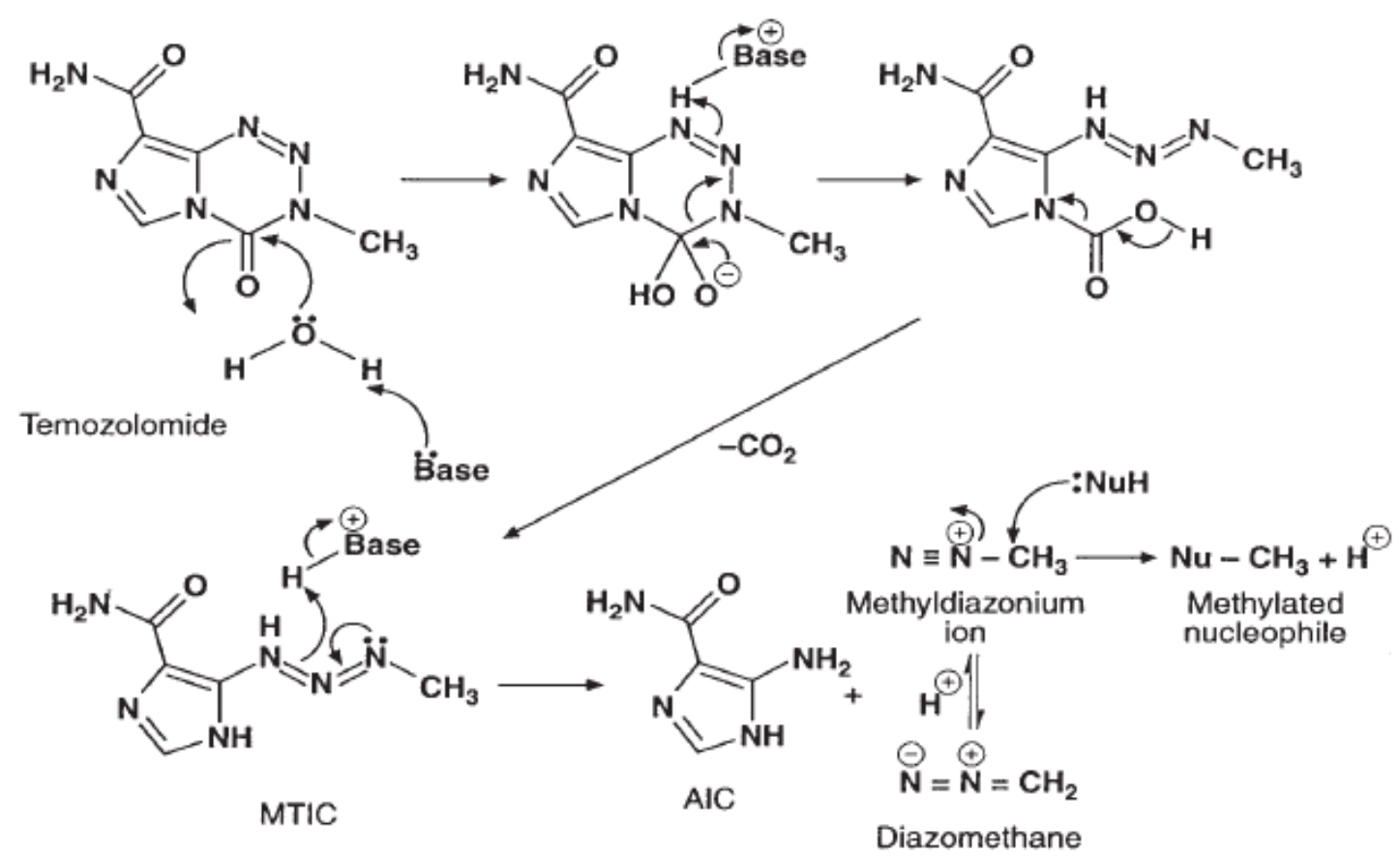

\section{Mechanisms of Resistance}

The two primary mechanisms of resistance for temozolomide and other alkylating agents are the enzyme AGT (alkylguanine alkyltransferase) [20,21] and a deficiency in the MMR (mismatch repair ) pathway. Of these two mechanisms, AGT plays a primary role in resistance to temozolomide by removing the alkyl groups from the $O^{6}$ position of guanine, in effect reversing the cytotoxic lesion of 
temozolomide [22]. The sensitivity of tumor cell lines to temozolomide and the alkylating agents BCNU and DTIC can be correlated with AGT levels [24-28]. Moreover, retrovirus-mediated transfer of human AGT gene to cells that are devoid of endogenous AGT activity confers a high level of resistance on temozolomide and other methylating and chloroethylating agents.

Despite the fact that AGT is clearly important in the resistance of cells to temozolomide, some cell lines that express low levels of AGT are nevertheless resistant, which suggests that other mechanisms for resistance may be implicated [29,30]. A insufficiency in the MMR pathway succeeded from mutations in any one or more of the five or six protein complexes that identify and correct DNA can ascribe cells tolerant to methylation and to the cytotoxic effects of temozolomide. This deficiency in the MMR pathway results in a failure to recognize and repair the $O^{6}$-MG adducts produced by temozolomide and other methylating agents [31-33]. DNA replication continues past the $O^{6}-\mathrm{MG}$ adducts without cell cycle arrest or apoptosis. Resistance in tumor cells that are deficient in MMR is unrelated to the level of AGT and is, therefore, unaffected by AGT inhibitors.

Another possible mechanism of resistance for temozolomide is the base excision repair pathway. Studies have shown that treatment of human tumor cells with temozolomide induced an increase in the activity of PARP (poly(ADP)-ribose polymerase), which is believed to be involved in nucleotide excision repair [34,35], and the inhibition of PARP has been reported to enhance the cytotoxicity of methylating agents [36-38]. Several studies with inhibitors of PARP and with cell lines deficient in either MMR or excision repair have indicated a role of the repair of $N^{7}$-methylguanine and $O^{3}$ methyladenine adducts in the resistance to the antitumor activity of temozolomide and other alkylating agents $[33,36,37,39]$. However, the importance of these adducts in the antitumor activity of the drug may be secondary to that of the $O^{6}-\mathrm{MG}$ adduct, except in those tumors that are deficient in base excision repair [40-42].

\section{Clinical pharmacology}

TMZ is rapidly absorbed after oral administration, and the bioavailability is approximately $100 \%$. The absorption of TMZ is only minimally affected by food. Absorption is reduced by only approximately $9 \%$ when taken with food, and this is not a clinically significant effect [43]. However, to reduce potential for nausea and vomiting, it is recommended that patients take TMZ at least $1 \mathrm{~h}$ before a meal or, preferably, at bedtime.

Phase I and II clinical studies have determined the maximum tolerated dose to be $1,000 \mathrm{mg} / \mathrm{m}^{2}$ divided over five days in each 28-day cycle [1-6]. TMZ is generally well tolerated at these dose levels. The most common nonhematologic adverse events are nausea, vomiting, headache, fatigue, and constipation. These events are generally mild to moderate in severity, and nausea and vomiting are readily controlled with standard antiemetics. With regard to hematologic toxicities, the incidence of grade $3 / 4$ neutropenia and thrombocytopenia is generally lower than $10 \%$, and fewer than $10 \%$ of patients required hospitalization, blood transfusion, or discontinuation of therapy due to myelosuppression. Myelosuppression is as a rule not cumulative and rarely results in discontinuation of treatment.

Based on the favorable toxicity profile observed in early clinical trials, subsequent studies have investigated doses of $150 \mathrm{mg} / \mathrm{m}^{2} /$ day $\chi 5$ days for patients who had previously been treated with 
cytotoxic chemotherapy (total dose $=750 \mathrm{mg} / \mathrm{m}^{2}$ per cycle), with a planned increase to $200 \mathrm{mg} / \mathrm{m}^{2} /$ day if no major myelosuppression was evident on day 22 of the 28-day cycle. For previously untreated patients, the initial dose is typically $200 \mathrm{mg} / \mathrm{m}^{2} /$ day $\chi 5$ days (total dose $=1,000 \mathrm{mg} / \mathrm{m}^{2}$ per cycle). A continuous oral dosing schedule has also been investigated in a phase I trial [44]. Administration of 75 $\mathrm{mg} / \mathrm{m}^{2} /$ day for six to seven weeks was well tolerated and resulted in a twofold increase in drug exposure over four weeks compared with the five-day every 28 days schedule. This regimen produced a 33\% objective response rate among 24 patients with varying tumor types, including 17 patients with gliomas. The continuous daily regimen lends itself to potential combination with fractionated radiation therapy.

The pharmacokinetics of TMZ after administration at 150 and $200 \mathrm{mg} / \mathrm{m}^{2}$ on a five-day schedule have been evaluated in humans (Table 1) [45]. The data indicate that TMZ is rapidly absorbed and eliminated. The mean time to maximal plasma concentration was less than $1 \mathrm{~h}$, and the mean terminal elimination half-life was approximately $1.8 \mathrm{~h}$. The maximum plasma concentration was 7.75 and 10.7 $\mathrm{mg} / \mathrm{ml}$ at the 150 and $200 \mathrm{mg} / \mathrm{m}^{2}$ doses, respectively. Figure 2 [46] shows the plasma concentration curve after oral administration of a single dose of TMZ ranging from 100 to $250 \mathrm{mg} / \mathrm{m}^{2}$. Nearly all of the administered dose was eliminated within $8 \mathrm{~h}$. Because of its rapid elimination and its mechanism of action, TMZ has a reduced risk of causing cumulative hematologic toxicity. The mean plasma area under the curve of TMZ after oral administration was 22.6 and $29.7 \mathrm{mg} \cdot \mathrm{h} / \mathrm{ml}$ after a dose of 150 and $200 \mathrm{mg} / \mathrm{m} 2$, respectively. These pharmacokinetic characteristics have been evaluated in a number of clinical studies and are consistent among studies and in different patient subgroups, including pediatric patients [5,47-49].

Figure 2. Shows the plasma concentration during time after oral administration of a single dose of temozolomide ranging from 100 to $250 \mathrm{mg} / \mathrm{m}^{2}$ [46].

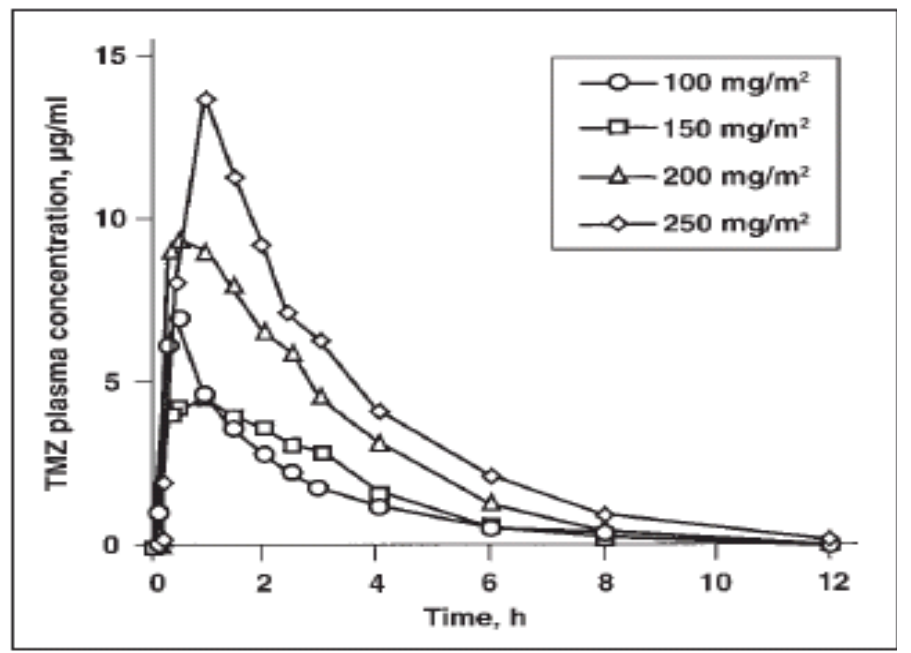


Table 1. Pharmacokinetics after single dose of temozolomide [45].

\begin{tabular}{|c|c|c|}
\hline & \multicolumn{2}{|c|}{ Oral dose } \\
\hline Parameter & $150 \mathrm{mg} / \mathrm{m}^{2} \quad(\mathrm{n}=12)$ & $200 \mathrm{mg} / \mathrm{m}^{2}(\mathrm{n}=6)$ \\
\hline $\mathrm{C}_{\max }$ & $7.75 \mu \mathrm{g} / \mathrm{mL}$ & $10.7 \mu \mathrm{g} / \mathrm{mL}$ \\
\hline $\mathrm{T}_{\max }$ & $0.85 \mathrm{~h}$ & $0.89 \mathrm{~h}$ \\
\hline AUC & $22.6 \mu \mathrm{g} \cdot \mathrm{h} / \mathrm{mL}$ & $29.7 \mu \mathrm{g} \cdot \mathrm{h} / \mathrm{mL}$ \\
\hline $\mathrm{T}_{1 / 2}$ & $1.81 \mathrm{~h}$ & $1.84 \mathrm{~h}$ \\
\hline Clearance & $3.05 \mathrm{~mL} / \mathrm{kg} / \mathrm{min}$ & $2.85 \mathrm{~mL} / \mathrm{kg} / \mathrm{min}$ \\
\hline Volume of distribution & $0.48 \mathrm{~L} / \mathrm{kg}$ & $0.45 \mathrm{~L} / \mathrm{kg}$ \\
\hline
\end{tabular}

$\mathrm{C}_{\text {max }}$ : maximum plasma concentration; $\mathrm{T}_{\max }$ : time of maximal concentration; AUC: area under the curve; $\mathrm{T}_{1 / 2}$ : terminal elimination half-life.

\section{Temozolomide in Malignant Gliomas}

Generally, HGGs have a poor prognosis, are rapidly progressive and resistant to therapy. Due to the fact that, they have an infiltrating they cannot be completely excised and the majority will recur within $2 \mathrm{~cm}$ of their original location. Median survival is around one year for GBM (gliblastoma multiform), two years for AA (anaplastic astrocytoma) and five years for AO (anaplastic oligodendroglioma) [50]. The main scope of the management is to achieve a symptomatic relief and increasing survival. The first option is surgery, which is usually required in some form for histological diagnosis. This may involve a biopsy or more aggressive resection. Currently there is no good evidence from RCTs (randomized controlled trails) that either approach results in any difference in survival over best medical care, although resection is commonly attempted where feasible [51]. Radiotherapy is the treatment with the greatest evidence base for effect and this is now part of standard management, resulting in an increase in median survival from three to four months to around nine to ten months [52]. The other principle therapy is glucocorticosteroids, which have an important role in the reduction of peri-tumoural oedema and can produce a marked improvement in neurological symptoms and survival by themselves [53].

Chemotherapy has been used as part of initial therapy as either single agent or multi-agent regimes to try and maximise penetration through the blood brain barrier and tumour responsiveness. The results have generally been interfering, and there is a meaningful morbidity associated with chemotherapy [54]. Recently a meta-analysis of chemotherapy in HGG has demonstrated an improvement in survival with PCV (procarbazine, carmustine, vincristine) chemotherapy (HR 0.85 CI 0.78 to $0.92 \mathrm{p}<0.0001$ ) with an overall improvement of two months in median survival to around 12 months [55]. It is not clear whether the gain in survival reflects a useful period of good QOL. In grade III tumours two recent RCTs did not demonstrate an increase in survival with PCV [56,57].

Temozolomide is a chemotherapeutic drug which is administered orally that methylates DNA in a way which prevents tumour cell proliferation. Early case series have suggested temozolomide to be a safe therapy with haematological toxicity in five to ten per cent, as well as being associated with a good median survival of around 16 months [58,59]. These survival figures compared favourably with expected prognosis in GBM, while toxicity was lower than with high dose procarbazine chemotherapy. Temozolomide is rapidly becoming standard therapy for GBM in the primary and recurrent disease settings, and has recently been licensed by the National Institute of Clinical Excellence in the UK in 
these disease settings. This practice has largely been based on a single high profile RCT although there is no full systematic review and meta-analysis in the field to fully assess the evidence basis for this trend in clinical practice.

\section{Combination of Temozolomide with Radiation Therapy}

TMZ alone has only a modest effect on high-grade glioma. It is mainly the interaction between TMZ and radiation therapy which is critical in the treatment of high grade glioma, especially in glioblastoma. The improvement effectiveness of combined TMZ and radiation therapy in patients with malignant glioma in comparison with radiation therapy alone was demonstrated in several preclinical and clinical studies. Wedge et al [60] have studied the in vitro cytotoxicity of 8-carbamoyl-3methylimidazo [5,1-d]-1,2,3,5-tetrazine-4(3H)-one (temozolomide) with concurrent X-irradiation in a human glioblastoma cell line (U373MG) as a potential radio-chemotherapeutic treatment for malignant glioma. The authors have concluded that the combination of temozolomide with radiation is at best additive, but could nonetheless by of considerable therapeutic benefit in glioma, particularly if administered for prolonged periods. Moreover, Hirose et al. [61] have studied the action of TMZ in gliomas and the role p53 might play by using U87 glioma cells that were either p53-wild-type or p53deficient (by virtue of expression of the viral oncoprotein E6). They have shown that glioma cells respond to TMZ by undergoing G2-M arrest. p53 is not necessary for this G2-M arrest to occur but is important in the duration of G2-M arrest and in the ultimate fate of TMZ-treated cells. Therefore, the integrity of the G2-M cell cycle checkpoint may be important in the cytotoxicity of TMZ in glioma cells. Additionally, Chakravarti et al. [62] have investigated the mechanisms by which temozolomide enhances radiation response in glioblastoma cells. They have shown that temozolomide enhances radiation response most effectively in $O^{6}$-methylguanine-DNA methyltransferase (MGMT)-negative glioblastomas by increasing the degree of radiation-induced double- strand DNA damage. In MGMTpositive glioblastomas, depletion of MGMT by the addition of $O^{6}$-benzylguanine significantly enhances the antitumor effect of concurrent radiation + temozolomide. Finally, Stupp et al. [63] recently have demonstrated that in a longer follow-up of five years, the patients with glioblastoma that received combined treatment with $\mathrm{TMZ}$ and radiation therapy have significantly better overall survival when compared with those that received radiation therapy alone. A few patients in favourable prognostic categories survive longer than five years. MGMT methylation status identifies patients most likely to benefit from the addition of temozolomide.

The main objective of this review article was to estimate the effectiveness of temozolomide in therapy of HGG as part of a) primary treatment and b) in recurrent disease. We have incorporated as eligible all randomized controlled trails that were consisted of two arms: first arm, intervention, patients that had received radiation therapy comcomitant with temozolomide and second arm, comparison, patients that had received radiation therapy only or radiation therapy in association with other form of chemotherapy e.g. PCV, Gliadel. The primary outcomes were survival from time to randomization to time of death, and secondary were: time to progression, quality of life and adverse events. 


\section{Eligible trials}

As regarding the effectiveness of temozolomide in therapy of HGG as part of primary treatment the literature research had shown that Two RCTs met the inclusion criteria. The first trial, involving 85 centres in 15 countries, was run by the EORTC (European Organization for Research and Treatment of Cancer) from August 2000 to March 2002 [64]. It evaluated concomitant and adjuvant temozolomide with radiotherapy in comparison with radiotherapy alone in primary therapy for histologically confirmed GBM only. Randomisation was adequate but the trial was not blinded and did not include a placebo. A total of 573 patients with newly histologically diagnosed GBM (at biopsy or resection) were included with inclusion criteria specifying age between 18 to 70 and a WHO (World Health Organization) performance score of 2 or less. Standard radiotherapy schedules of 60 Gy for six weeks were given to both arms. The temozolomide schedules was $75 \mathrm{mg} / \mathrm{m}^{2}$ daily during radiotherapy then up to 6 adjuvant cycles of 150 to $200 \mathrm{mg} / \mathrm{m}^{2}$ for five out of 28 days for a total of six cycles. No routine chemotherapy was given to the control arm. Subsequent management was given according to need with no pre-specified protocol mentioned. The primary end point was overall survival. Secondary endpoints included progression free survival and safety. A follow up article was published describing only the QOL results from the initial trial run by the EORTC [65]. This used the EORTC QLQ-C30 and QLQ-BCM20 as combined outcome measures which were then converted to a score of 0 to 100 . The difference between groups and from baseline was recorded for seven groups (overall, fatigue, social function, emotional function, future uncertainty, insomnia and communication deficit). Compliance with questionnaires was also recorded. The second trial was also published in 2005 and was set in Greece [66]. It used a dose intensification schedule of temozolomide in the adjuvant phase involving $150 \mathrm{mg} / \mathrm{m}^{2}$ of temozolomide on days 1 to 5 and 15 to 19 . In the concomitant phase temozolomide was administered using a standard $75 \mathrm{mg} / \mathrm{m}^{2}$. Radiotherapy was administered to both arms in a dose of 60 Gy over 6 weeks. Randomisation was adequate but the trial was not blinded and did not include a placebo. A total of 130 patients were randomised, with inclusion criteria specifying GBM on histology, Karnofsky Performance Scale of 60 or more, and age over 18 (but with no upper age limit specified). Poor medical condition was an exclusion factor. Primary outcome measures were overall survival and time to progression. Secondary outcome measures included toxicity.

For recurrent disease we have found only one eligible trial that was a randomised, multicentre, open-label phase II study comparing temozolomide with procarbazine for first relapse of GBM [67]. A total of 225 patients were randomised between January 1995 and October 1997 and subject to an intention to treat analysis. Randomisation was deemed to be adequate but was not blinded. Temozolomide was administered on days 1 to 5 out of 28 and procarbazine administered for 28 days out of every 56. No radiotherapy was administered to either arm. Primary outcome measures were progression free survival and overall survival. Secondary outcome measures were health related QOL (measured by EORTC QLQ-C30 and QLQ-BCM20), objective responsiveness and toxicity/adverse events. Table 2 summarizes the characteristics of eligible trials for both primary and recurrent disease. 
Table 2. Characteristics of eligible trials.

\begin{tabular}{|c|c|c|c|c|}
\hline \multicolumn{5}{|c|}{ Primary therapy } \\
\hline Author & $\begin{array}{l}\text { Year } \\
\text { published } \\
\text { Type of trial }\end{array}$ & $\begin{array}{l}\text { Number of } \\
\text { patients }\end{array}$ & Treatment schecule & Outcomes \\
\hline $\begin{array}{l}\text { Athanasiou } \\
\text { [66] }\end{array}$ & 2005, RCT & 130 & $\begin{array}{l}\text { Concomitant TMZ daily } \\
\text { with RT for } 6 \text { weeks. } \\
\text { Adjuvant TMZ on days 1-5 } \\
\text { and } 15-19 \text { for less than } 6 \\
\text { cycles. }\end{array}$ & $\begin{array}{l}\text { Primary: Survival; } \\
\text { PFS. Secondary: } \\
\text { Safety }\end{array}$ \\
\hline Stupp [64] & 2005, RCT & 573 & $\begin{array}{l}\text { Concomitant daily TMZ } \\
(75 \mathrm{mg} / \mathrm{m} 2 / \text { day) during RT } \\
(<7 \mathrm{weeks}) \text {. Adjuvant TMZ } \\
\text { for first } 5 \text { days out of } \\
28 \text { for } 6 \text { or fewer cycles. RT } \\
\text { was } 60 \mathrm{~Gy} \text { focally to the } \\
\text { tumour and a } 2-3 \mathrm{~cm} \text { margin } \\
\text { over } 30 \text { sessions and } 6 \\
\text { weeks. }\end{array}$ & $\begin{array}{lr}\text { Primary: Survival. } \\
\text { Seconday: PFS, } \\
\text { Safety, QoL }\end{array}$ \\
\hline \multicolumn{5}{|c|}{ Recurrent disease } \\
\hline Yung [67] & 2000, RCT & 225 & $\begin{array}{l}\text { Temozolomide: } \\
200 \mathrm{mg} / \mathrm{m} 2 / \text { day (if } \\
\text { chemotherapy naive) or } \\
150 \mathrm{mg} / \mathrm{m} 2 / \text { day (if prior } \\
\text { chemotherapy) for } \\
5 \text { days out of a } 28 \text { day cycle. } \\
\text { Procarbazine } 150 \mathrm{mg} / \mathrm{m} 2 / \text { day } \\
\text { (chemotherapy naive) or } \\
125 \mathrm{mg} / \mathrm{m} 2 / \text { day (if } \\
\text { prior chemotherapy) for } 28 \\
\text { consecutive days in a } 56 \text { day } \\
\text { cycle }\end{array}$ & $\begin{array}{l}\text { Objective } \\
\text { response, } \\
\text { sixmonth } \\
\text { PFS,median PFS, } \\
\text { survival, adverse } \\
\text { events }\end{array}$ \\
\hline
\end{tabular}

Abbreviations: RCT: randomized controlled trials, TMZ: temozolomide, PFS: progression free survival, RT: radiation therapy, QoL: quality of life.

\section{Results}

For primary therapy temozolomide resulted in an increase in survival (HR $0.84,95 \%$ CI 0.50 to $0.68, \mathrm{p}<0.001)$ compared with the control arm. Fixed effects models were used as the entry criteria for each study were broadly inclusive. As only two trials were included and both demonstrated a survival benefit individually it was apparent that there was no gross heterogeneity between the trials and a formal statistical test of heterogeneity was deemed unneccessary. There was also an increase in time to progression with temozolomide (HR $0.52,0.42$ to $0.64, \mathrm{p}<0.001$ ). For QOL there was no difference between the two arms for any of the seven outcome measures (overall, fatigue, social function, emotional function, future uncertainty, insomnia and communication deficit). Due to the low 
level of adverse events these are presented in a descriptive manner. In the trial Stupp et al. [64] grade $3 / 4$ haematologic toxicity occurred in $7 \%$ during concomitant therapy and $14 \%$ in the adjuvant phase. Events lead to treatment discontinuation in $8 \%$. No haematologic toxicity was noted in the control arm. No statistical difference in severe infections, fatigue or thromboembolic events was reported between either arm. Athanassiou et al. [66] grade 3/4 haematologica toxicity was reported in the concomitant phase as leucopenia in $3.5 \%$ and thrombocytopenia in $5.2 \%$. In the adjuvant phase the results were leucopenia in $2 \%$ and thrombocytopenia in $5 \%$. Non-haematological side effects were rash $5 \%$, constipation $3.5 \%$ and arthralgia $1.5 \%$.

As regarding therapy for recurrent diseas, temozolomide was effective in increasing time to progression (HR 0.68, CI 0.51 to $0.90, \mathrm{p}=0.008$ ) but not in increasing survival (HR 0.87, CI 0.65 to $1.16, \mathrm{p}=0.34)$. No appropriate data was available for calculation of QOL outcomes. Adverse events were noted in $77 \%$ of the temozolomide group and $76 \%$ of the procarbazine group. Grade $3 / 4$ adverse events were found in $18 \%$ of the temozolomide group and $25 \%$ of the procarbazine group. Haematological adverse events were low at fewer than $7 \%$ in both groups but were not cummulatively compared; there did not appear to be a difference in the individual subgroups of haematological adverse events. Drop outs due to adverse events were: temozolomide 3\% versus procarbazine $11 \%$. The most common side effecs of all grades were: nausea (temozolomide 38\% versus procarbazine $34 \%$ ), vomiting (temozolomide $32 \%$ versus procarbazine $27 \%$ ) and fatigue (temozolomide $27 \%$ and procarbzine $15 \%$ ).

\section{Conclusions}

Temozolomide is an effective p.o. administered anticancer agent that demonstrates a broad spectrum of activity in various solid tumors and distribution to all tissues, including the brain. It spontaneously converts to an active methylating agent with activity against a number of refractory cancers, including malignant glioma, metastatic melanoma, and other solid tumors. Temozolomide is well tolerated, with minimal myelosuppression that is noncumulative and with nonhematological toxicity that is easily managed with standard antiemetic agents. Unique characteristics of stability and solubility allow temozolomide to be absorbed readily and distributed to all tissues with approximately $100 \%$ bioavailability after p.o. administration. Thus, temozolomide does not require hepatic metabolism for activation and is capable of penetrating the blood-brain barrier. Temozolomide demonstrates dose-linear PK (pharmacokinetic), is cleared rapidly, and does not accumulate with repeat dosing. Its PK yields little intrasubject or intersubject variability, which is manifested by its predictable clinical tolerance and mild side effect profile.

The literature research indicates that temozolomide is effective as primary therapy for GBM. It prolongs survival and time to progression without a significant risk of early adverse events. It appears to be most effective in young and fit patients with GBM who have had debulking surgery. These results are based on two RCTs of 703 patients in total. Recently, the updated Phase III trial by the European Organisation for Research and Treatment of Cancer (EORTC) and National Cancer Institute of Canada Clinical Trials Group (NCIC) reported a benefit of combined therapy in all clinical prognostic subgroups, including patients aged 60-70 years. Methylation of the MGMT promoter was the strongest predictor for outcome and benefit from temozolomide chemotherapy. Temozolomide is 
also effective as therapy for recurrent disease, where it increases time to progression without an increase in adverse events. There are still some reservations with this data as the trials were not blinded or placebo controlled, whilst quality of life data could be further expanded upon. In a well selected subgroup of patients with GBM, temozolomide vindicate consideration for use as in either primary or recurrent disease settings, but decisions need to be made on an individual patient basis as part of a multi-disciplinary meeting discussion. Further trials are needed with improved methodology, including placebo control, blinding, and the use of clear statistical reporting of outcome measures in particular for recurrence and QoL.

\section{References and Notes}

1. O'Reilly, S.M.; Newlands, E.S.; Glaser, M.G.; Brampton, M.; Rice-Edwards, J.M.; Illingworth, R.D.; Richards, P.G.; Kennard, C.; Colquhoun, I.R.; Lewis, P. Temozolomide: A new cytotoxic agent with promising activity against primary brain tumors. Eur. J. Cancer 1993, 29, 940-942.

2. Newlands, E.S.; O’Reilly, S.M.; Glaser, M.G.; Bower, M.; Evans, H.; Brock, C.; Brampton, M.H.; Colquhoun, I.; Lewis, P.; Rice-Edwards, J.M.; Illingworth, R.; Richards, P.G. The Charing Cross Hospital experience with temozolomide in patients with gliomas. Eur. J. Cancer 1996, 32A, 2236-2241.

3. Bower, M.; Newlands, E.S.; Bleehen, N.M.; Brada ,M.; Begent, R.J.; Calvert, H.; Colquhoun, I.; Lewis, P.; Brampton, M.H. Multicentre CRC phase II trial of temozolomide in recurrent orprogressive highgrade glioma. Cancer Chemother. Pharmacol. 1997, 40, 484-488.

4. Yung, W.K.; Prados, M.D.; Yaya-Tur, R.; Rosenfeld, S.S.; Brada, M.; Friedman, H.S.; AlbrightR.; Olson, J.; Chang, S.M.; O’Neill, A.M.; Friedman, A.H.; Bruner, J.; Yue, N.; Dugan, M.; Zaknoen, S.; Levin, V.A. Multicenter phase II trial of temozolomide in patients with anaplastic astrocytoma or anaplastic oligoastrocytoma at first relapse. J. Clin. Oncol. 1999, 17, 2762-2771.

5. Newlands, E.S.; Blackledge, G.R.; Slack, J.A.; Rustin, G.J.; Smith, D.B.; Stuart ,N.S.; Quarterman, C.P.; Hoffman, R.; Stevens, M.F.; Brampton, M.H. Phase I trial of temozolomide (CCRG 81045: M\&B 39831: NSC 362856). Br. J. Cancer 1992, 65, 287-291.

6. Bleehen, N.M.; Newlands, E.S.; Lee, S.M.; Can Thatcher, N.; Selby, P.; Calvert, A.H.; Rustin, G.J.; Brampton, M.; Stevens, M.F. cer Research Campaign phase II trial of temozolomide in metastatic melanoma. J. Clin. Oncol. 1995, 13, 910-913.

7. Middleton, M.R.; Lunn, J.M.; Morris, C.; Rustin, G.; Wedge, S.R.; Brampton, M.H.; Lind, M.J.; Lee, S.M.; Newell, D.R.; Bleehen, N.M.; Newlands, E.S.; Calvert, A.H.; Margison, G.P.; Thatcher, N. O6-Methylguanine- DNA methyltransferase in pretreatment tumour biopsies as a predictor of response to temozolomide in melanoma. Br. J. Cancer 1998, 78, 1199-1202.

8. Stevens, M.F.; Hickman, J.A.; Stone, R.; Gibson, N.W.; Baig, G.U.; Lunt, E.; Newton, C.G. Antitumor imidazotetrazines. 1. Synthesis and chemistry of 8-carbamoyl-3-(2chloroethyl)imidazo[5,1-d]-1,2,3,5-tetrazin-4(3 H)-one, a novel broad-spectrum antitumor agent. J. Med. Chem. 1984, 27, 196-201. 
9. Newlands, E.S.; Stevens, M.F.G.; Wedge, S.R.; Wheelhouse, R.T.; Brock, C. Temozolomide: A review of its discovery,chemical properties, pre-clinical development and clinical trials. Cancer Treat. Rev. 1997, 23, 35-61.

10. Patel, M.; McCully, C.; Godwin, K. Plasma and cerebrospinal fluid pharmacokinetics of temozolomide. Proc. Am. Soc. Clin. Oncol. 1995, 14, 461a.

11. Newlands, E.S.; Blackledge, G.R.P.; Slack, J.A.; Rustin, G.J.S.; Smith, D.B.; Stuart, N.S.A.; Quarterman, C.P.; Hoffman, R.; Stevens, M.F.G.; Brampton, M.H.; Gibson, A.C. Phase I Trial of temozolomide (CCRG 81045: M\&B 39831: NSC 362856). Br. J. Cancer 1992, 65, 287-291.

12. Bleehen, N.M.; Newlands, E.S.; Lee, S.M.; Thatcher, N.; Selby, P.; Calvert, A.H.; Rustin, G.J.S.; Brampton, M.; Stevens, M.F.G. Cancer Research Campaign Phase II trial of temozolomide in metastatic melanoma. J. Clin. Oncol. 1995, 1, 910-913.

13. O'Reilly, S.M.; Newlands, E.S.; Glaser, M.G.; Brampton, M.; Rice-Edwards, J.M.; Illingworth, R.D.; Richards, P.G.; Kennard, C.; Colquhoun, I.R.; Lewis, P.; Stevens, M.F.G. Temozolomide: a new oral cytotoxic chemotherapeutic agent with promising activity against primary brain tumours. Eur. J. Cancer 1993, 29A, 940-942.

14. Bower, M.; Newlands, E.S.; Bleehen, N.M.; Brada, M.; Begent, R.J.H.; Calvert, H.; Colquhoun, I.; Lewis, P.; Brampton, M.H. Multicentre CRC Phase II trial of temozolomide in recurrent or progressive high-grade glioma. Cancer Chemother. Pharmacol. 1997, 40, 484-488.

15. Paulsen, F.; Hoffmann, W.; Becker, G.; Belka, C.; Weinmann, M.; Classen, J.; Kortmann, R.D.; Bamberg, M. Chemotherapy in the treatment of recurrent glioblastoma multiforme: ifosfamide versus temozolomide. J. Cancer Res. Clin. Oncol. 1999, 125, 411-418.

16. Estlin, E.J.; Lashford, L.; Ablett, S.; Price, L.; Gowing, R.; Gholkar, A.; Kohler, J.; Lewis, I.J.; Morland, B.; Pinkerton, C.R.; Stevens, M.C.G.; Mott, M.; Stevens, R.; Newell, D.R.; Walker, D.; Dicks- Mireaux, C.; McDowell, H.; Reidenberg, P.; Statkevich, P.; Marco, A.; Batra, V.; Dugan, M.; Pearson, A.D.J. Phase I study of temozolomide in paediatric patients with advanced cancer. United Kingdom Children's Cancer Study Group. Br. J. Cancer. 1998, 78, 652-661.

17. Nicholson, H.S.; Krailo, M.; Ames, M.M.; Seibel, N.L.; Reid, J.M.; Liu-Mares, W.; Vezina, L.G.; Ettinger, A.G.; Reaman, G.H. Phase I study of temozolomide in children and adolescents with recurrent solid tumors: a report from the Children's Cancer Group. J. Clin. Oncol. 1998, 16, 3037-3043.

18. Stevens, M.F.; Hickman, J.A.; Langdon, S.P.; Chubb, D.; Vickers, L.; Stone, R.; Baig, G.; Goddard, C.; Gibson, N.W.; Slack, J.A. Antitumor activity and pharmacokinetics in mice of 8carbamoyl-3-methyl-imidazo[5,1-d]-1,2,3,5-tetrazin-4(3H)-one (CCRG 81045; M \& B39831), a novel drug with potential as an alternative to dacarbazine. Cancer Res. 1987, 47, 5846-5852.

19. Ostermann, S.; Csajka, C.; Buclin, T.; Leyvraz, S.; Lejeune, F.; Decosterd, L.A.; Stupp, R. Plasma and cerebrospinal fluid population pharmacokinetics of temozolomide in malignant glioma patients. Clin. Cancer Res. 2004, 10, 3728-3736

20. Pegg, A.E.; Dolan, M.E.; Moschel, R.C. Structure, function, and inhibition of O6- alkylguanineDNA alkyltransferase. Prog. Nucleic Acid Res. Mol. Biol. 1995, 51, 167-223.

21. D'Incalci, M.; Citti, L.; Taverna, P.; Catapano, C.V. Importance of the DNA repair enzyme O6alkyl guanine alkyltransferase (AT) in cancer chemotherapy. Cancer Treat. Rev. 1988, 15, 279292. 
22. Pegg, A.E.; Byers, T.L. Repair of DNA containing O6- alkylguanine. FASEB J. 1992, 6, 23022310.

23. Tisdale, M.J. Antitumor imidazotetrazines-XV. Role of guanine O6 alkylation in the mechanism of cytotoxicity of imidazotetrazinones. Biochem. Pharmacol. 1987, 36, 457-462.

24. Baer, J.C.; Freeman, A.A.; Newlands, E.S.; Watson, A.J.; Rafferty, J.A.; Margison, G.P. Depletion of O6-alkylguanine-DNA alkyltransferase correlates with potentiation of temozolomide and CCNU toxicity in human tumour cells. Br. J. Cancer 1993, 67, 1299-1302.

25. Redmond, S.M.; Joncourt, F.; Buser, K.; Ziemiecki, A.; Altermatt, H.J.; Fey, M.; Margison, G.; Cerny, T. Assessment of P-glycoprotein, glutathione-based detoxifying enzymes and O6alkylguanine-DNA alkyltransferase as potential indicators of constitutive drug resistance in human colorectal tumors. Cancer Res. 1991, 51, 2092-2097.

26. Franchi, A.; Papa, G.; D’Atri, S.; Piccioni, D.; Masi, M.; Bonmassar, E. Cytotoxic effects of dacarbazine in patients with acute myelogenous leukemia: a pilot study. Haematologica 1992, 77, 146-150.

27. D’Atri, S.; Piccioni, D.; Castellano, A.; Tuorto, V.; Franchi, A.; Lu, K.; Christiansen, N.; Frankel, S.; Rustum, Y.M.; Papa, G.; Mandelli, F.; Bonmassar, E. Chemosensitivity to triazene compounds and O6- alkylguanine-DNA alkyltransferase levels: studies with blasts of leukaemic patients. Ann. Oncol. 1995, 6, 389-393.

28. Tentori, L.; Graziani, G.; Gilberti, S.; Lacal, P.M.; Bonmassar, E.; D’Atri, S. Triazene compounds induce apoptosis in O6-alkylguanine- DNA alkyltransferase deficient leukemia cell lines. Leukemia 1995, 9, 1888-1895.

29. Walker, M.C.; Masters, J.R.W.; Margison, G.P. O6-alkylguanine- DNA-alkyltransferase activity and nitrosourea sensitivity in human cancer cell lines. Br. J. Cancer 1992, 66, 840-843.

30. Bobola, M.S.; Tseng, S.H.; Blank, A.; Berger, M.S.; Silber, J.R. Role of O6-methylguanine-DNA methyltransferase in resistance of human brain tumor cell lines to the clinically relevant methylating agents temozolomide and streptozotocin. Clin. Cancer Res. 1996, 2, 735-741.

31. Liu, L.; Markowitz, S.; Gerson, S.L. Mismatch repair mutations override alkyltransferase in conferring resistance to temozolomide but not to 1,3-bis(2-chloroethyl)nitrosourea. Cancer Res. 1996, 56, 5375-5379.

32. Friedman, H.S.; Johnson, S.P.; Dong, Q.; Schold, S.C.; Rasheed, B.K.A.; Bigner, S.H.; AliOsman, F.; Dolan, E.; Colvin, O.M.; Houghton, P.; Germain, G.; Drummond, J.T.; Keir, S.; Marcelli, S.; Bigner, D.D.; Modrich, P. Methylator resistance mediated by mismatch repair deficiency in a glioblastoma multiforme xenograft. Cancer Res. 1997, 57, 2933-2936.

33. Wedge, S.R.; Porteous, J.K.; Newlands, E.S. 3-aminobenzamide and/or O6-benzylguanine evaluated as an adjuvant to temozolomide or BCNU treatment in cell lines of variable mismatch repair status and O6-alkylguanine-DNA alkyltransferase activity. Br. J. Cancer 1996, 74, 10301036.

34. Tisdale, M.J. Antitumour imidazotetrazines-XI: effect of 8-carbamoyl- 3-methylimidazo[5,1-d]1,2,3,5-tetrazin-4(3H)-one [CCRG 81045; M and B 39831 NSC 362856] on poly(ADP-ribose) metabolism. Br. J. Cancer 1985, 52, 789-792.

35. Durkacz, B.W.; Omidiji, O.; Gray, D.A.; Shall, S. (ADPribose) n participates in DNA excision repair. Nature (Lond.).1980, 283, 593-596. 
36. Boulton, S.; Pemberton, L.C.; Porteous, J.K.; Curtin, N.J.; Griffin, R.J.; Golding, B.T.; Durkacz, B.W. Potentiation of temozolomideinduced cytotoxicity: a comparative study of the biological effects of poly(ADP-ribose) polymerase inhibitors. Br. J. Cancer 1995, 72, 849-856.

37. Wu, Z.; Chan, C.L.; Eastman, A.; Bresnick, E. Expression of human O6-methylguanine-DNA methyltransferase in Chinese hamster ovary cells and restoration of cellular resistance to certain $N$-nitroso compounds. Mol. Carcinog. 1991, 4, 482-488.

38. Tentori, L.; Turriziani, M.; Franco, D.; Serafino, A.; Levati, L.; Roy, R.; Bonmassar, E.; Graziani, G. Treatment with temozolomide and poly(ADP-ribose) polymerase inhibitors induces early apoptosis and increases base excision repair gene transcripts in leukemic cells resistant to triazene compounds. Leukemia 1999, 13, 901-909.

39. Liu, L.; Taverna, P.; Whitacre, C.M.; Chatterjee, S.; Gerson, S.L. Pharmacologic disruption of base excision repair sensitizes mismatch repair-deficient and -proficient colon cancer cells to methylating agents. Clin. Cancer Res. 1999, 5, 2908-2917.

40. Catapano, C.V.; Broggini, M.; Erba, E.; Ponti, M.; Mariani, L.; Citti, L.; D’Incalci, M. In vitro and in vivo methazolastone-induced DNA damage and repair in L-1210 leukemia sensitive and resistant to chloroethylnitrosoureas. Cancer Res. 1987, 47, 4884-4889.

41. Deans, B.; Tisdale, M.J. Antitumour imidazotetrazines XXVIII 3-methyladenine DNA glycosylase activity in cell lines sensitive and resistant to temozolomide. Cancer Lett. 1992, 63, 151-157.

42. Imperatori, L.; Damia, G.; Taverna, P.; Garattini, E.; Citti, L.; Boldrini, L.; D’Incalci, M. 3T3 NIH murine fibroblasts and B78 murine melanoma cells expressing the Escherichia coli N3methyladenine-DNA glycosylase I do not become resistant to alkylating agents. Carcinogenesis (Lond.) 1994, 15, 533-537.

43. Reidenberg, P.; Statkevich, P.; Judson, I. Effect of food on the oral bioavailability of temozolomide, a new chemotherapeutic agent. Proc. Am. Soc. Clin. Pharmacol. Ther. 1996, 59, 199a.

44. Brock, C.S.; Newlands, E.S.; Wedge, S.R.; Bower, M.; Evans, H.; Colquhoun, I.; Roddie, M.; Glaser, M.; Brampton, M.H.; Rustin, G.J. Phase I trial of temozolomide using an extended continuous oral schedule. Cancer Res. 1998, 58, 4363-4367.

45. Kenilworth, N.J. Data on File. Schering-Plough Corporation: New Jersey, USA, 1998.

46. Kenilworth, N.J. Data on File. Study CI93-114. Schering-Plough Corporation: New Jersey, USA, 1998.

47. Nicholson, H.S.; Ames, M.M.; Krailo, M. Phase I and pharmacokinetic study of temozolomide (TEM) in children and adolescents. A report from the Children's Cancer Group (CCG). Proc. Am. Soc. Clin. Oncol. 1995, 14, 449a.

48. Dhodapkar, M.; Reid, J.; Ames, M.M. Phase I clinical trial and pharmacokinetics of temozolamide (NSC 362856). Proc. Am. Assoc. Cancer Res. 1994, 35, $245 \mathrm{a}$.

49. Eckardt, J.R.; Weiss, G.R.; Burris, H.A. Phase I clinical trial and pharmacokinetic trial of SCH52365 (temozolomide) given orally daily' 5 days. Proc. Am. Soc. Clin. Oncol. 1995, 14, 484a. 
50. Winger, M.J.;Macdonald, D.R.; Cairncross, J.G. Supratentorial anaplastic gliomas in adults. The prognostic importance of extent of resection and prior low-grade glioma. J. Neurosurg. 1989, 71, 487-493.

51. Hart, M.G.; Grant, R.; Metcalfe, S.E. Biopsy versus resection for High Grade Glioma. Cochrane Database Sys. Rev. 2000, Issue 2.

52. Walker, M.D.; Alexander, E., Jr.; Hunt, W.E.; MacCarty, C.S.; Mahaley, M.S., Jr.; Mealey, J., Jr. Evaluation of BCNU and/or radiotherapy in the treatment of anaplastic gliomas. A cooperative clinical trial. J. Neurosurg. 1978, 49, 333-343.

53. Kaal, E.C.A.; Vecht, C.J. The management of brain edema in brain tumours. Curr. Opin. Oncol. 2004, 16, 593-600.

54. Rampling, R.; James, A.; Papanastassoiu, V. The Present and Future Management of Malignant Brain Tumours: Surgery, Radiotherapy, Chemotherapy. J. Neurol. Neurosurg. Psychiatry 2005, 75(Suppl II), 24-30.

55. Glioma Meta-Analysts Trialists (GMT) Group. Chemotherapy for High Grade Glioma. Cochrane Database Sys. Rev. 2002, Issue 3.

56. Cairncross, G.; Berkey, B.; Shaw, E.;Jenkins, R.; Scheithauer, B.; Brachman, D. Phase III Trial of Chemotherapy Plus Radiotherapy Compared With Radiotherapy Alone for Pure and Mixed Anaplastic Oligodendroglioma: Intergroup Radiation Therapy Oncology Group Trial 9402. J. Clin. Oncol. 2006, 24, 18, 2707-2714.

57. Van den Bent, M.J.;Carpentier, A.F.; Brandes, A.A.; Sanson,M.; Taphoorn, M.J.; Bernsen, H.J.; renay, M.; Tijssen, C.C.; Grisold, W.; Sipos, L.; Haaxma-Reiche, H.; Kros, J.M.; van Kouwenhoven, M.C.; Vecht, C.J.; Allgeier, A.; Lacombe, D.; Gorlia, T. Adjuvant procarbazine, iomustine and vincristine improves progression-free survival but not overall survival in newly diagnosed anaplastic oligodendrogliomas and oligoastrocytomas: A randomized european organisation for research and treatment of cancer phase III trial. J. Clin. Oncol. 2006, 24, 27152722.

58. Lanzetta, G.; Campanella, C.; Rozzi, A.; Nappa, M.; Costa, A.; Fedele, F.; Innocenzi, G.; Agliardi, F.M.; Salvati, M.; Minniti, G.; Frati, A.; Frati, L.; Vecchione, A. Temozolamide in radio-chemotherapy combined treatment for newly-diagnosed glioblastoma multiforme: Phase II clinical trial. Anticancer Res. 2003, 23, 5159-5164.

59. Stupp, R.; Dietrich, P.Y.; Ostermann Kraljevic, S.; Pica, A.; Maillard, I.; Maeder, P.; Meuli, R.; Janzer, R.; Pizzolato, G.; Miralbell, R.; Porchet, F.; Regli, L.; de Tribolet, N.; Mirimanoff, R.O.; Leyvraz, S. Promising survival for patients with newly diagnosed glioblastoma multiforme treated with concomitant radioation plus temozolamide followed by adjuvant temozolamdide. J. Clin. Oncol. 2002, 20, 1375-1382.

60. Wedge, S.R.; Porteous, J.K.; Glaser, M.G; Marcus, K.; Newlands, E.S. In vitro evaluation of temozolomide combined with X-irradiation. Anticancer Drugs 1997, 8, 92-97.

61. Hirose,Y.; Berger, S.M.; Russell, O.P. p53 Effects Both the Duration of G2/M Arrest and the Fate of Temozolomide-treated Human Glioblastoma Cells. Cancer Res. 2001, 61, 1957-1963.

62. Chakravarti, A.; Erkkinen,G.M.; Nestler, U.; Stupp, R.; Mehta, M.; Aldape, K.; Gilbert, R.M.; Black, P.; Loeffler, S.J.; Temozolomide-Mediated Radiation Enhancement in Glioblastoma: A Report on UnderlyingMechanisms. Clin. Cancer Res. 2006, 12, 4738-4746. 
63. Stupp, R.; Hegi, M.E.; Mason, W.P.; van den Bent, M.J.; Taphoorn, M.J.; Janzer, R.C.; Ludwin, S.K.; Allgeier, A.; Fisher, B.; Belanger, K.; Hau, P.; Brandes, A.A.; Gijtenbeek, J.; Marosi, C.; Vecht, C.J.; Mokhtari, K.; Wesseling, P.; Villa, S.; Eisenhauer, E.; Gorlia, T.; Weller, M. Effects of radiotherapy with concomitant and adjuvant temozolomide versus radiotherapy alone on survival in glioblastoma in a randomised phase III study: 5-year analysis of the EORTC-NCIC trial. Lancet. Oncol. 2009, Mar 6, [Epub ahead of print].

64. Stupp, R.; Mason, W.P.; van den Bent, M.J.; Weller, M.; Fisher, B.; Taphoorn, M.J.; Belanger, K.; Brandes, A.A.; Marosi, C.; Bogdahn, U.; Curschmann, J.; Janzer, R.C.; Ludwin, S.K.; Gorlia, T.; Allgeier, A.; Lacombe, D.; Cairncross, J.G.; Eisenhauer, E.; Mirimanoff, R.O. Radiotherapy plus Concomitant and Adjuvant Temozolomide for Glioblastoma. N. Engl. J. Med. 2005, 352, 987-996.

65. Taphoorn, M.J.; Stupp, R.; Coens, C.; Osoba, D.; Kortmann, R.; van den Bent, M.J.; Mason, W.; Mirimanoff, R.O.; Baumert, B.G.; Eisenhauer, E.; Forsyth, P. Bottomley A Health-related quality of life in patients with glioblastoma: A randomised controlled trial. Lancet. Oncol. 2005, 6, $937-$ 944.

66. Athanassiou, H.; Synodinou, M.; Maragoudakis, E.; Paraskevaidis, M.; Verigos, C.; Misailidou, D.; Antonadou, D.; Saris, G.; Beroukas, K.; Karageorgis, P. Randomised Phase II study of Temozolomide and Radiotherapy Compared with Radiotherapy Alone in Newly Diagnosed Glioblastoma Multiforme. J. Clin. Oncol. 2005, 23, 2372-2377.

67. Yung, A.; Levin, V.A.; Albright, A. Randomized trial of temodal (TEM) vs. procarbazine (PCB) in glioblastoma multiforme (GBM) at first relapse. Proc. Am. Soc. Clin. Oncol. 2000, 18, 139.

Sample availability: Not available.

(C) 2009 by the authors; licensee Molecular Diversity Preservation International, Basel, Switzerland. This article is an open-access article distributed under the terms and conditions of the Creative Commons Attribution license (http://creativecommons.org/licenses/by/3.0/). 